\title{
BASELINE ASSESSMENTS OF WILDLIFE BIODIVERSITY WITHIN SELECTED AREAS OF CENTRAL VISAYAS, PHILIPPINES
}

\author{
Jose, R. P., W. A. Aureo, C. I. Narido ${ }^{1}$, T. D. Reyes Jr. ${ }^{2}$ and M. B. Sarnowski ${ }^{3}$ \\ Department of Forestry and Environmental Science, College of Agriculture and Natural Resources, \\ Bohol Island State University, Zamora, Bilar, Bohol, Philippines, ${ }^{1}$ Biology Section, Department of \\ Mathematics and Natural Sciences, College of Arts and Sciences, Holy Name University, Tagbilaran \\ City, Philippines, ${ }^{2}$ Institute of Renewable Natural Resources, College of Forestry and Natural \\ Resources, University of the Philippines-Los Banos, Philippines; ${ }^{3}$ Peace Corps Response, United States \\ Peace Corps, Manila, Philippines

\begin{abstract}
A comprehensive inventory of faunal biodiversity was conducted within three Key Biodiversity Areas of Central Visayas. Mt. Bandilaan Natural Park (MBNP), Balinsasayao Twin Lakes Natural Park (BTLNP), and Rajah Sikatuna Protected Landscape (RSPL). Three primary wildlife groups were surveyed: bats, birds and amphibians. Species diversity and population trends were then analyzed to assess areas of biodiversity importance. RSPL generally had the highest species richness and diversity index while MBNP consistently had the lowest. When pooled. The surveyed areas resulted in a high diversity index and rate of endemicity showing the importance of multiple areas of protection. These findings can be utilized to prioritize habitat protection as well as to serve as a baseline information for future biodiversity inventories.
\end{abstract}

Key words: Biodiversity; Conservation; Environmental management; Philippines.

\section{INTRODUCTION}

The Philippines is rich in biodiversity with over 1000 terrestrial species (DENR-UNEP 1997). However, these species reside in some of the most critically threatened habitat and species in the world (Heaney and Regalado 1998). Within the Philippines, Central Visayas is considered as a distinct biogeographic region that share exclusively many similar species occur in the other region of the country. This makes some of its ecologically important fauna remarkably unique from one island to another within the region (Fernando et al. 2009). This diversity is in jeopardy as rapid destruction and alteration of tropical rain forests has drastically change native habitats (Posa et al. 2008).

It is timely that these areas, being habitats of ecologically important and highly threatened fauna be assessed for conservation and proper management. The Philippines has taken initial steps in preserving these habitats and species through the establishment of Key Biodiversity Areas (KBAs). Currently, 228 KBAs have been established covering over $100,000 \mathrm{~km}^{2}$ (Ambal et al. 2012).

The aim of this inventory is to identify and document vertebrate wildlife, with a focus on bats, avifauna, and amphibians, in the selected KBAs of Central Visayas. The gathered data will enhance awareness of significant species of three wildlife groups, identify specific areas of high biodiversity, and guide wildlife conservation and management efforts. These efforts will help conserve existing endemic and threatened species as well as aid future studies. Analyses of species' populations will help to inform stakeholders and key decision makers in actions necessary for the conservation and protection of the fauna in the said areas.

Study Area

\section{MATERIAL AND METHODS}

Three Key Biodiversity Areas within the Central Visayas region of the Philippines were surveyed (Fig. 1). Key Biodiversity Areas assessed were: Mt. Bandilaan Natural Park (MBNP) - Siquijor Island 
from, Balinsasayao Twin Lakes Natural Park (BTLNP) - Negros Oriental from, and Rajah Sikatuna Protected Landscape (RSPL) - Bohol from February to October 2019.

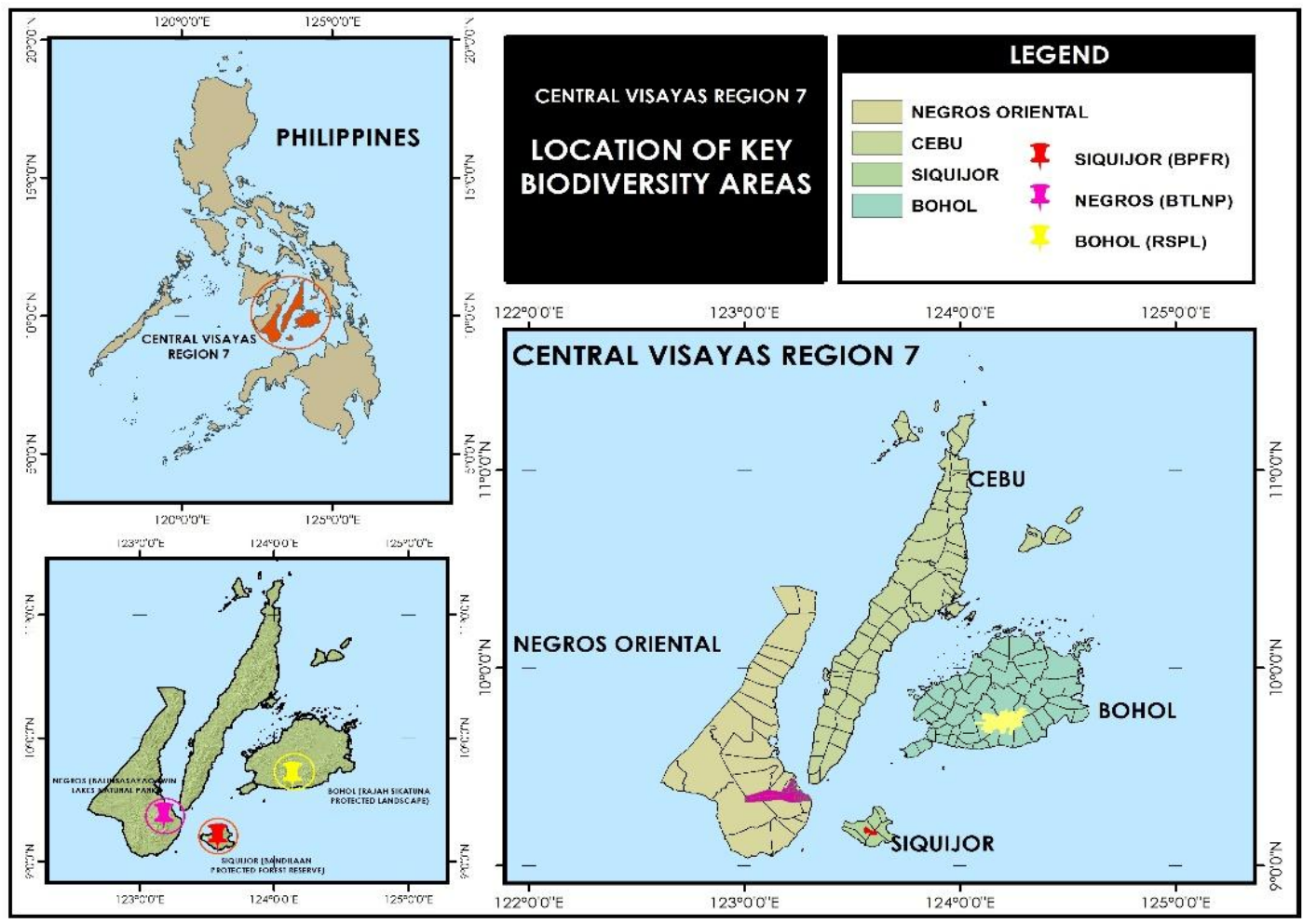

Fig. 1. Location of selected Key Biodiversity Areas.

\section{Assessment of Vertebrate Fauna}

Bats

Night time mist netting was employed to capture bats. Nets were placed in predicted flyways and moved frequently (as often as nightly) as catch rates drop dramatically after animals become aware of the net placement. Net checks were conducted in the early evening and every 30 minutes thereafter. Captured bats were placed in separate cloth bags which were labeled with capture site. A sugar solution was available for frugivous bats to restore energy stores. Bats were identified to species level using "A Key to the Bats of the Philippine Islands" (Ingle and Heaney 1992). Morphometries were measured using a ruler or caliper. Sex, weight, age, reproductive status (i.e. lactating, with pup) and any abnormalities were also noted. Prior to being released, a mark was made with indelible ink to detect any recaptures.

\section{Avifauna}

Bat mist nets double for bird sampling as they were placed in fly ways and near food sources. Nets were checked at dusk and dawn and throughout the day if the net was not moved to a new site and left open. Once birds were removed from the netting they were placed in cloth bags labeled with capture site and processed. Transect walks utilized observational and auditory methods were also used in order to supplement the mist netting as some birds were inadequately represented in net captures.

Morphometries were taken through the use of a caliper. "A Guide to the Birds of the Philippines" (Kennedy et al. 2000) was utilized for species identification. Tail feathers were clipped to denote capture after which subjects were released. 


\section{Amphibians}

One kilometer transects were established throughout the surveyed areas. Amphibians were collected utilizing the Visual Encounter Survey in the early morning from 6:00-9:00 am and in the evening from 7:00-10:00 pm (Warguez et al. 2013). Areas of survey focus were places of high potential including the surface and under rocks, logs, trees, and other debris within each established transect. Morphometric measurements were taken using a caliper. Species identification was performed using the field guide of Diesmos and Alcala (2011) and IUCN List of Threatened Species.

\section{Biodiversity Indices}

Species counts were further analyzed for biodiversity indices. Calculations included species richness, species diversity (Shannon Index- H'), and percent endemicity. Animals that could not be identified to a species level were included in species richness and diversity calculations if they were confirmed to be separate species from known specimens. However, these species were excluded for endemicity calculations. All calculations were performed utilizing formulas within Microsoft Excel.

\section{RESULTS AND DISCUSSION}

Bat species distribution, diversity, richness and endemicity

A total of 14 species of bats in six families were recorded, five $(36 \%)$ of which are endemic to the Philippines (Table 1). Eight species of fruit bats (Suborder Megachiroptera) and six species of insect bats (Suborder Microchiroptera) were netted.

Table 1. Bat species captured and their distribution/conservation status.

\begin{tabular}{|c|c|c|c|c|c|c|}
\hline Family & Scientific Name & Distribution/status & MBNP & BTLNP & RSPL & Total \\
\hline \multirow{8}{*}{ Pteropodidae } & Cynopterus brachyotis & $\mathrm{W} / \mathrm{LC}$ & 45 & 100 & 156 & 301 \\
\hline & Eonycteris spelaea & $\mathrm{W} / \mathrm{LC}$ & - & 6 & 22 & 28 \\
\hline & Haplonycteris fischeri & $\mathrm{PE} / \mathrm{LC}$ & - & 69 & - & 69 \\
\hline & Macroglossus minimus & $\mathrm{W} / \mathrm{LC}$ & 4 & 53 & 37 & 94 \\
\hline & Nyctimene rabori & $\mathrm{PE} / \mathrm{EN}$ & - & 1 & - & 1 \\
\hline & Ptenochirus jagori & $\mathrm{PE} / \mathrm{LC}$ & 82 & 60 & 256 & 398 \\
\hline & Pteropus pumilus & $\mathrm{PE} / \mathrm{NT}$ & - & 1 & - & 1 \\
\hline & Rousettus amplexicaudatus & $\mathrm{W} / \mathrm{LC}$ & 3 & 8 & 134 & 145 \\
\hline Megadermatidae & Megaderma Spasma & $\mathrm{W} / \mathrm{LC}$ & 2 & 1 & - & 3 \\
\hline \multirow{2}{*}{ Hipposideridae } & Hipposideros diadema & $\mathrm{W} / \mathrm{LC}$ & 8 & - & 30 & 38 \\
\hline & Hipposideros ater & $\mathrm{W} / \mathrm{LC}$ & - & - & 1 & 1 \\
\hline Rhinolophidae & Rhinolophus arcuatus & $\mathrm{W} / \mathrm{LC}$ & 6 & 1 & 12 & 19 \\
\hline Rhinolophidae & Rhinolophus rufus & $\mathrm{PE} / \mathrm{NT}$ & - & - & 1 & 1 \\
\hline Vespertilionidae & Miniopterus australis & $\mathrm{W} / \mathrm{LC}$ & 1 & - & - & 1 \\
\hline
\end{tabular}

Distribution: W- Widespread; PE- Philippine Endemic; Status (IUCN 2016) LC- Least Concern; EN- Endangered; NT- Near Threatened

P. jagori, a species endemic to the Philippines, was the most prolific capture with 398 animals caught across the sites while five species only had one capture. Species diversity was low across all sites $\left(H^{\prime}=1.24-1.58\right)$ due to the limited number of species caught. Species richness was relatively equal between sites but endemicity varied greatly with the highest rate (40\%) observed at MBNP (Fig. 2).

Of the previously recorded bat species, $57 \%$ were captured in Siquijor, $27 \%$ in Negros Oriental, and 26\% in Bohol (Heaney et al. 1998 and Jakosalem et al. 2005). The rarity of insect bats caught could be attributed to the method used (mist netting) as insect bats might detect the net using their echolocation ability and therefore avoid capture. In addition, relatively few caves were observed in the sampling sites, which may contribute to the low catch as insect bats are known to thrive in this habitat. 


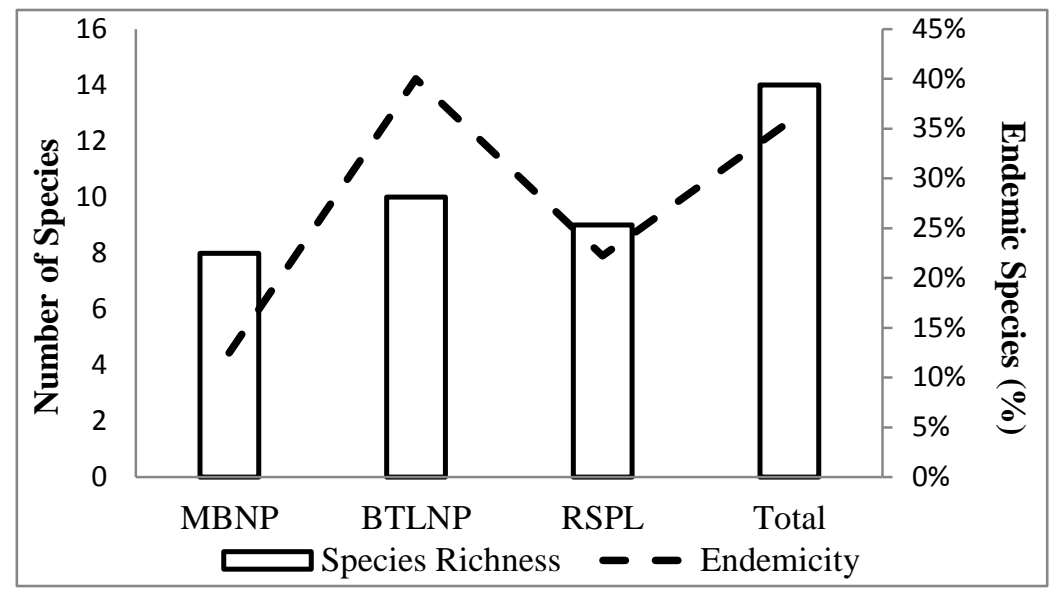

Fig. 2. Bat endemicity and species richness across sites.

Avifauna species distribution, diversity, richness and endemicity

The combined field techniques yielded a total of 31 species of birds in 21 families were recorded, 12 $(40 \%)$ of which are endemic to the Philippines (Table 2).

Table 2. Bird species captured and their distribution/conservation status.

\begin{tabular}{llccccc}
\hline Family & Scientific Name & Distribution/status & MBNP & BTLNP & RSPL & Total \\
\hline Acedinidae & Ceyx Lepidus & W/LC & 5 & - & - & 5 \\
& Actenoides lindsayi & PE/LC & - & 2 & - & 2 \\
& Todiramphus chloris & W/LC & - & - & 2 & 2 \\
\hline Apodidae & Collocalia troglodytes & W/LC & 11 & 1 & - & 12 \\
\hline Columbidae & Chalcophaps indica & W/LC & 1 & 1 & 1 & 3 \\
& Phapitreron leucotis & PE/LC & - & 1 & 3 & 4 \\
& Ptilinopus leclancheri & W/LC & - & - & 1 & 1 \\
\hline Cuculidae & Cacomantis variolosus & W/LC & - & 1 & - & 1 \\
\hline Dicaeidae & Dicaeum trigonostigma & W/LC & 1 & 2 & 2 & 5 \\
& Prionochilus olivaceus & PE/LC & - & - & 1 & 1 \\
\hline Dicruridae & Dicrurus balicassius & PE/LC & - & 2 & 3 & 5 \\
\hline Estrildidae & Lonchura leucogastra & W/LC & 1 & - & 4 & 5 \\
\hline Eurylaimidae & Eurylaimus steerii & PE/V & - & - & 1 & 1 \\
\hline Laniidae & Lanius cristatus & W/LC & - & 2 & - & 2 \\
\hline Monarchidae & Hypothymis azurea & W/LC & 1 & - & 1 & 2 \\
\hline Muscicapidae & Cyornis rufigastra & W/LC & 3 & - & - & 3 \\
& Cyornis ruficauda & W/LC & - & - & 1 & 1 \\
\hline Pachycephalidae & Pachycephala philippensis & PE/LC & 2 & - & - & 2 \\
& Pachycephala homeyeri & W/LC & - & 1 & 2 & 3 \\
\hline Phylloscopidae & Phylloscopus cebuensis & PE/LC & - & 1 & - & 1 \\
\hline Pittidae & Pitta sordid & W/LC & 1 & - & - & 1 \\
\hline Podargidae & Batrachostomus septimus & PE/LC & - & 1 & - & 1 \\
\hline Pycnonotidae & Hypsipetes siquijorensis & PE/EN & 12 & - & - & 12 \\
& Hypsipetes philippinus & PE/LC & - & 5 & 1 & 6 \\
& Poliolophus urostictus & PE/LC & - & - & 2 & 2 \\
\hline Rhipidurudae & Rhipidura superciliaris & PE/LC & - & - & 1 & 1 \\
\hline Strigidae & Ninox scutulata & W/LC & - & 2 & - & 2 \\
\hline Sturnidae & Aplonis panayensis & W/LC & 4 & - & - & 4 \\
& Otus sp. & Unknown & - & 1 & 1 & 2 \\
\hline Trogonidae & Harpactes ardens & PE/LC & - & - & 1 & 1 \\
\hline Tyrannidae & Myiarchus sp. & Unknown & - & - & 1 & 1 \\
\hline
\end{tabular}

Distribution: W- Widespread; PE- Philippine Endemic; Status (IUCN 2016) LC- Least Concern; EN- Endangered; NT- Near Threatened 
C. troglodytes and $H$. siquijorensis were the most frequently captured species, of which all but one capture was at MBNP. Eleven species had only one incident of capture. Species diversity was moderate within the individual sites but approaching high when all sites are combined. Although BTLNP and RSPL had less animals captures, these sites both had higher species diversity $\left(\mathrm{H}^{\prime}=2.48\right.$ and 2.76, respectively) than MBNP $\left(H^{\prime}=1.97\right)$ where more species were caught. Lower richness and endemicity was observed in MBNP while BTLNP and RSPL were more similar to each other (Fig. 3).

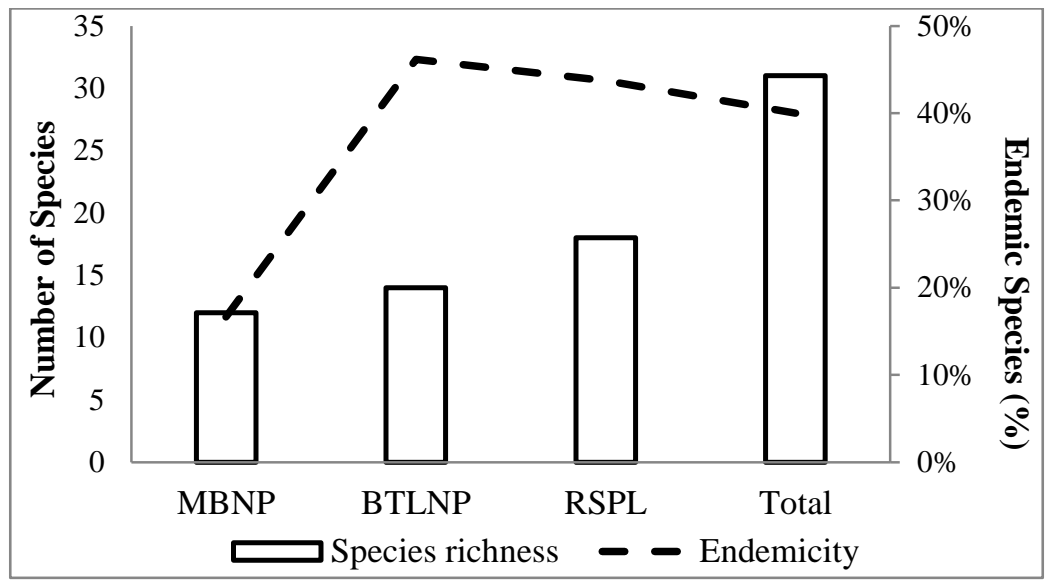

Fig. 3. Endemicity and species richness of birds across sites.

Bat mist netting sites frequently doubled as bird capture sites. This may result in birds of similar habitat preferences and flight patterns to be captured more frequently and a reduced number of ground or high flying birds captured

Amphibian species distribution, diversity, richness and endemicity

A total of 19 species of amphibians in seven families were recorded, ten (63\%) of which are endemic to the Philippines (Table 3).

Table 3. Amphibian species captured and their distribution/conservation status.

\begin{tabular}{|c|c|c|c|c|c|c|}
\hline Family & Scientific Name & Distribution/status & MBNP* & BTLNP* & RSPL & Total \\
\hline Bufonidae & Rhinella marina & $\mathrm{W} / \mathrm{LC}$ & 1 & 1 & - & 2 \\
\hline \multirow{2}{*}{ Ceratobatrachidae } & Platymantis corrugatus & $\mathrm{PE} / \mathrm{LC}$ & 1 & 1 & 59 & 61 \\
\hline & Platymantis sp. & unknown & 1 & - & - & 1 \\
\hline \multirow{4}{*}{ Ceratobatrachidae } & Platymantis hazelae & $\mathrm{PE} / \mathrm{V}$ & - & 1 & 44 & 45 \\
\hline & Platymantis dorsalis & $\mathrm{PE} / \mathrm{LC}$ & - & 1 & - & 1 \\
\hline & Platymantis negrosensis & $\mathrm{PE} / \mathrm{NT}$ & - & 1 & - & 1 \\
\hline & Platymantis guentheri & $\mathrm{PE} / \mathrm{LC}$ & - & - & 38 & 38 \\
\hline \multirow{3}{*}{ Dicroglossidae } & Occidozyga laevis & $\mathrm{W} / \mathrm{LC}$ & 1 & 1 & 10 & 12 \\
\hline & Limnonectes visayanus & $\mathrm{PE} / \mathrm{NT}$ & 1 & 1 & 34 & 36 \\
\hline & Fejervarya moodiei & $\mathrm{PE} / \mathrm{LC}$ & - & - & 17 & 17 \\
\hline Megophryidae & Megophrys stejnegeri & $\mathrm{PE} / \mathrm{LC}$ & - & - & 13 & 13 \\
\hline Microhylidae & Kalophrynus pleurostigma & $\mathrm{W} / \mathrm{LC}$ & - & - & 25 & 25 \\
\hline \multirow{3}{*}{ Ranidae } & Pulchrana grandocula & $\mathrm{PE} / \mathrm{LC}$ & - & - & 25 & 25 \\
\hline & Sanguirana sp. & unknown & - & - & 12 & 12 \\
\hline & Staurois natator & $\mathrm{PE} / \mathrm{LC}$ & - & - & 7 & 7 \\
\hline \multirow{3}{*}{ Rhacophoridae } & Rhacophorus pardalis & $\mathrm{W} / \mathrm{LC}$ & 1 & 1 & 4 & 6 \\
\hline & Polypedates leucomystax & $\mathrm{W} / \mathrm{LC}$ & 1 & 1 & 11 & 13 \\
\hline & Philautus sp. & unknown & - & - & 14 & 14 \\
\hline
\end{tabular}

*- Number of individuals captured not noted, only presence of species; Distribution: W- Widespread; PE- Philippine Endemic; Status (IUCN, 2016) LC- Least Concern; V- Vulnerable; NT- Near Threatened 
Species composition varied greatly between sites. While some species were found within multiple KBAs, other species were only found in one park. Species diversity was moderate across all sites $\left(\mathrm{H}^{\prime}=\right.$ 1.95-2.43), however this a compromised calculation as capture rates for MBNP and BTLNP were not recorded. Species richness and endemicity varied between sites with MBNP having the lowest in both richness and endemicity and RSPL having the highest of these categories. Over double the number of species, 15 vs 7, were found in RSPL compared to MBNP.

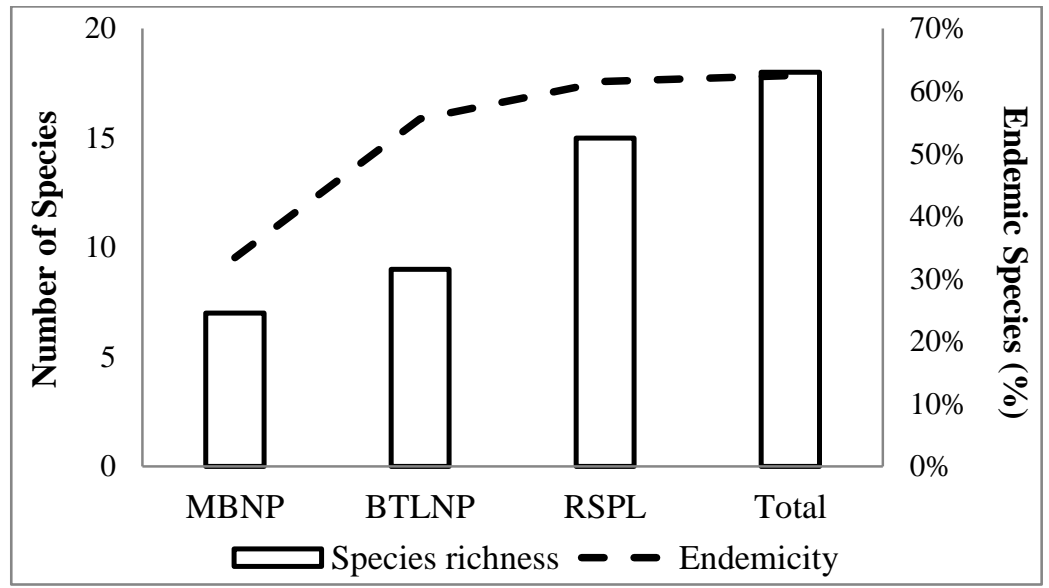

Fig. 4. Endemicity and species richness of amphibians across sites.

There was a difficulty of finding anurans at Mr. Bandilaan and Mt. Balinsasayao as during the sampling period, there was little rain and ground conditions were dry.

\section{Combined species}

A total of 65 species were recorded, $45 \%$ of which are endemic to the Philippines. Overall species richness and endemicity was lowest in MBNP with 27 species captured of which $19 \%$ were endemic. A high rate of endemicity was observed in RSPL and BTLNP with $45 \%$ and $47 \%$, respectfully. Cumulative species diversity was moderate across all sites with a high total diversity for all sites combined (Fig. 5).

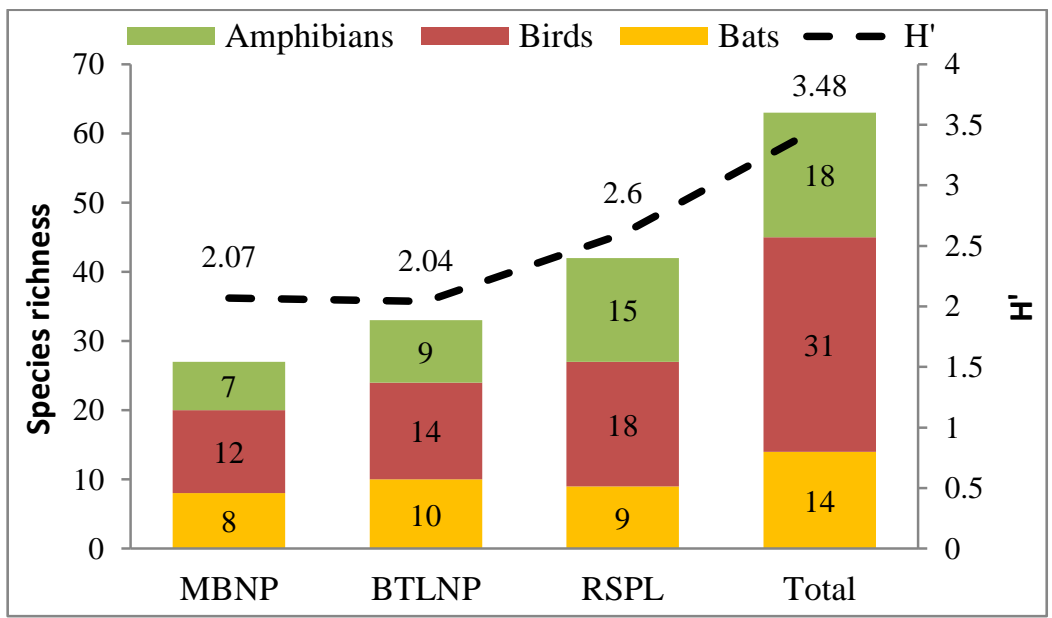

Fig. 5. Species richness and diversity within each site.

Biodiversity remains strong within the surveyed KBAs. While this initial evaluation of some wildlife diversity did not capture all known species within the region, this does not necessarily indicate 
decreasing biodiversity in the area. Many factors such as weather, capture methods, and time of year may have impacted the detection of some species. Rather, this assessment serves as a general description of the KBA faunal diversity.

It is possible that species diversity was impacted by the size of the protected area. The smallest park, MBNP, had the overall lowest number of endemic species, species richness, and the second lowest species diversity. However, BTLNP and RPSL which are similar in size frequently had comparable results. Management must take this into consideration when prioritizing practices. Is it more prudent to focus resources on conserving a small area with lower diversity or to protect a larger area with higher species richness and endemicity. If the trend of endemicity focusing is prioritized (Saout et al. 2013) then RSPL and BTLNP would be important stake holder investments.

Fortunately, this is not necessarily that a decision that needs to be made. Although protected by the federal government, KBAs are under local control (Posa et al. 2008). However, many lack active protection (Ambal et al. 2012). Habitat loss was noted in surrounding, and sometimes, within the study sites. This habitat disturbance could lead to population restriction or the possible loss of species (Laurance et al. 2012). Smaller areas, such as MBNP, could be more significantly impacted by neighboring disturbance as they do not have as many resources to provide refuge for displaced animals. It is therefore vital to work with the local communities to ensure continued, or in some cases increased, protection of these natural reserves.

Protection of these valuable species is key to maintaining a resilient ecosystem (Oliver et al. 2015). Through monitoring and proactive management, these KBAs can be maintained as an oasis for the plethora of species found within them. Continued species monitoring will help to maintain a sustainable and diverse future for these areas.

\section{ACKNOWLEDGEMENTS}

The authors express their gratitude to the Philippine Council for Agriculture, Aquatic and Natural Resources Research and Development (PCAARRD) for funding the project. The Department of Environment and Natural Resources (DENR) and the Protected Area Management Board (PAMB) members of MBNP, BTLNP and RSPL are also acknowledged for allowing the researchers to proceed with the conduct of their study. Also, appreciation is expressed to Balinsasayao-Twin Lakes People's Organization (BTLNP), local guides and the surveyed communities for welcoming the team during the conduct of the study.

\section{REFERENCES}

Ambal, R. G. R., M. V. Duya, M. A. Cruz, O. G. Coroza, S. G. Vergara, N. de Silva, N. Molinyawe and B. Tabaranza. 2012. Key Biodiversity Areas in the Philippines: Priorities for Conservation. $J$. Threatened Taxa. 4(8): 2788-2796.

Department of Environment and Natural Resources/United Nations Environment Program. 1997. Philippine Biodiversity: An Assessment and Action Plan. Bookmark Inc. Manila, Philippine.

Fernando, E. S., M. J. M. Bande, R. A. Piollo, D. D. Sopot, N. E. Dolotina and W. G. Granert. 2009. Dipterocarpaceae of Bohol Island, Philippines. Asia Life Sci. 18(1): 122.

Heaney, L. R. and J. C. Regalado Jr. 1998. Vanishing Treasures of the Philippines Rain Forest. J. Mammology. 82(1): 246-247.

Heaney, L. R., D. S. Balete, M. L. Dolar, A. C. Alcala, A. T. L. Dans, P. C. Gonzales, N. R. Ingle, M. V. Lepiten, W. L. R. Oliver, P. S. Ong, E. A. Rickart, B. R. Tabaranza Jr. and R. C. B. Utzurrum. 
1998. A Synopsis of the mammalian fauna of the Philippine Islands. Fieldiana: Zoology. The Field Museum, Chicago, IL.

Ingle, N. R. and L. R. Heaney. 1992. A key to the bats of the Philippine Islands. Fieldiana: Zoology. 69: 1-44.

Jakosalem, P. G. C., L. M. J. Paguntalan, M. Pedregosa and M. J. G. Catacutan. 2005. Distribution and conservation importance of volant mammals in Siquijor Island, the Philippines. The Philippine Scientist. 42: 159-170.

Kennedy, R. S., P. C. Gonzales, E. C. Dickinson, H. C. J. Miranda, and T. H. Fisher. 2000. A Guide to the Birds of the Philippines. Oxford University Press, Oxford, UK.

Laurance, W. F., D. C. Useche, J. Rendeiro, M. Kalka, C. J. Bradshaw, S. P. Sloan, and V. ArroyoRodriguez. 2012. Averting biodiversity collapse in tropical forest protected areas. Nature. 489(7415): 290.

Oliver, T. H., M. S. Heard, N. J. Isaac, D. B. Roy, D. Procter, F. Eigenbrod and V. Proenca. 2015. Biodiversity and resilience of ecosystem functions. Trends Ecol. Evol. 30(11): 673-684.

Posa, M. R. C., A. C. Diesmos, N. S. Sodhi and T. M. Brooks. 2008. Hope for threatened tropical biodiversity: lessons from the Philippines. BioScience. 58(3): 231-240.

Saout, S., M. Hoffmann, Y. Shi, A. Hughes, C. Bernard, T. M. Brooks, B. Bertzky, S. H. M. Butchart, S. N. Stuart, T. Badman and A. S. Rodrigues. 2013. Protected areas and effective biodiversity conservation. Science. 342(6160): 803-805.

Warguez, D. A., E. P. Mondejar and C. G. Demayo. 2013. Frogs and their Microhabitat Preferences in the Agricultural and Secondary Forest areas in the Vicinity of Mt. Kalatungan Mountain, Bukidnon, Philippines. Int. Res. J. Biol. Sci. 2: 2278-3202. 